\title{
Eggs of Phasmid Species in the North Island
}

\author{
By R. A. CUMBER,
}

Entomology Division, Department of Scientific and Industrial Research, Palmerston North.

When searching through leaf-mould samples from forested areas, one may often encounter the eggs of "stick insects." These are by no means always obvious, since in sifting, they usually reach the sample which contains frass materials of similar proportions and size-a feature which might well bestow survival value.

During the past five years, a selection of these eggs has been kept, and the variation in form and sculpturing is quite impressive. This variation, coming as it cloes in the egg stage, must be of considerable systematic significance.

The literature on New Zealand phasmids up to 1952 is indicated by Miller (1956). Salmon (1954, 1955 a-c) has made further contributions. There is little reference to the character of the eggs, however.

It would be of considerable interest to know which species are involved in the eggs pictured in the present paper. Doubtless further distinctive egg forms are present in this country-especially in the South Island, and high country areas. Studies may well show characteristic egg forms in the different genera. Adults taken during the summer months and held in captivity for short periods may be expected to oblige, and so help unravel this fascinating facet of our entomology.

\section{REFERENCES}

Miller, D., 1956. Bibliography of New Zealand Entomology. N.Z. Dep. Sci. Industr. Res. Bull. 120: 492 pp.

Salmon, J. T., 1954. A New Genus and Species of Phasmidae from New Zealand. Trans. Roy. Soc. N.Z. 82: 161-68.

1955a. The Genus Acanthoxyla (Phasmidae). Ibid. 82: 1149-56. 1955b. Parthenogenesis in New Zealand Stick Insects. Ibid. 82: 1189-92.

1955c. Stick Insects. Tuatara 5 (3): 77-81. 


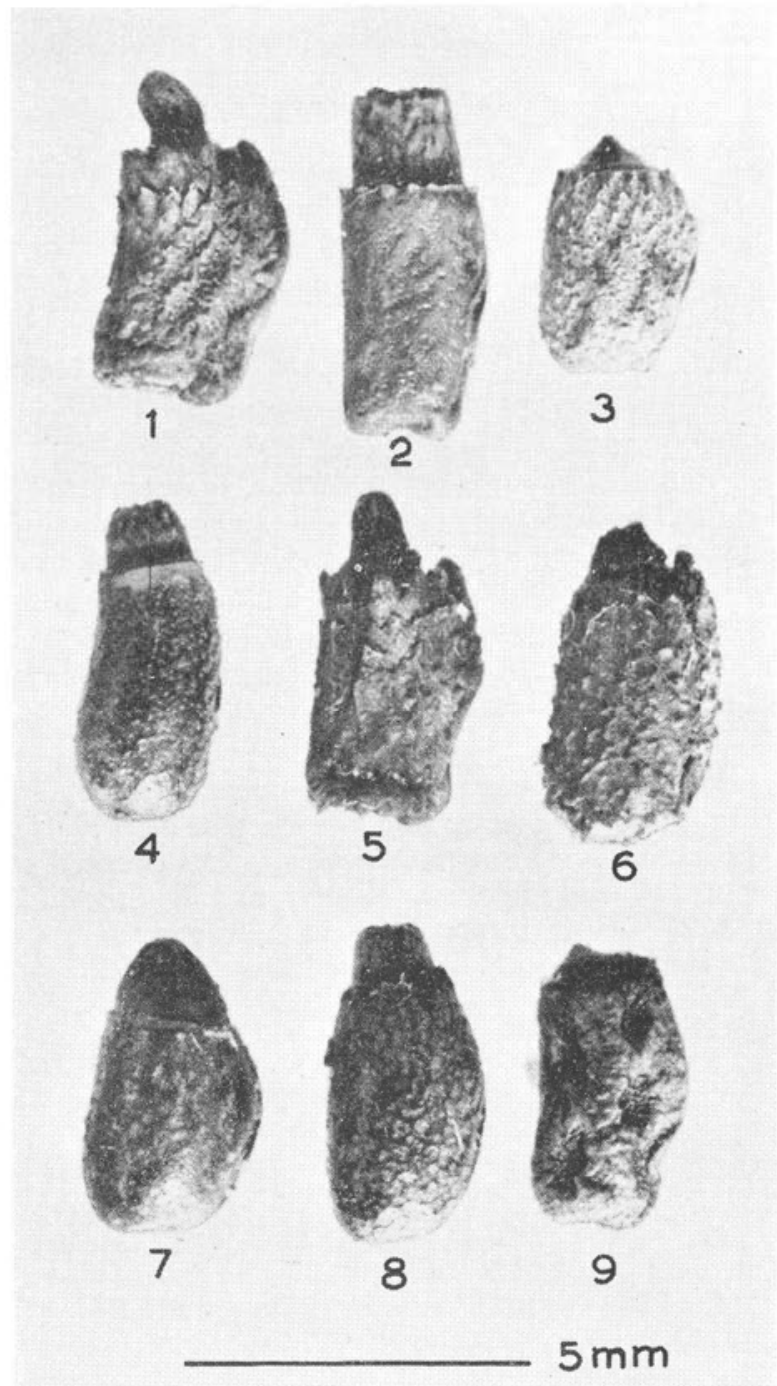

Phasmid egg capsules from leaf-mould samples: 1 . Kahuterawa, Northern Tararua Range, 27/4/61; 2. Wharite, Southern Ruahine Range, 3/9/58; 3. Bal1ance Bridge, Manawatu Gorge, 28/1/59; 4. Waitakere Range, 3/9/58; 5. Mangamuka Gorge, Northland, 23/2/59; 6. Aorangi Mountains, Wairarapa, 24/1/59; 7. Waiare, near Kaeo, Northland, 19/9/58; 8. Wharite, Southern Ruahine Range, 3/9/58; 9. Wimbledon, Southern Hawke's Bav, 26/11/57.

Photograph Miss M. Soulsby. 